\title{
Taser X26 Discharges in Swine: Ventricular Rhythm Capture is Dependent on Discharge Vector
}

\author{
Daniel J. Valentino, MD, Robert J. Walter, PhD, Andrew J. Dennis, DO, Bosko Margeta, MD, \\ Frederic Starr, MD, Kimberly K. Nagy, MD, Faran Bokhari, MD, Dorion E. Wiley, MD, \\ Kimberly T. Joseph, MD, and Roxanne R. Roberts, $M D$
}

Background: Data from our previous studies indicate that Taser X26 stun devices can acutely alter cardiac function in swine. We hypothesized that most transcardiac discharge vectors would capture ventricular rhythm, but that other vectors, not traversing the heart, would fail to capture the ventricular rhythm.

Methods: Using an Institutional Animal Care and Use Committee (IACUC) approved protocol, four Yorkshire pigs (25-36 kg) were anesthetized, paralyzed with succinylcholine $(2 \mathrm{mg} / \mathrm{kg})$, and then exposed to 10 second discharges from a police-issue Taser X26. For most discharges, the barbed darts were pushed manually into the skin to their full depth $(12 \mathrm{~mm})$ and were arranged in either transcardiac (such that a straight line connecting the darts would cross the region of the heart) or non-transcardiac vectors. A total of 11 different vectors and 22 discharge conditions were studied. For each vector, by simply rotating the cartridge 180-degrees in the gun, the primary current-emitting dart was changed and the direction of current flow during the discharge was reversed without physically moving the darts. Echocardiography and electrocardiograms (ECGs) were performed before, during, and after all discharges. $p$ values $<0.05$ were considered significant.

Results: ECGs were unreadable during the discharges because of electrical interference, but echocardiography images clearly demonstrated that ventricular rhythm was captured immediately in $\mathbf{5 2 . 5 \%}$ (31 of 59) of the discharges on the ventral surface of the animal. In each of these cases, capture of the ventricular rhythm with rapid ventricular contractions consistent with ventricular tachycardia (VT) or flutter was seen throughout the discharge. A total of 27 discharges were administered with transcardiac vectors and ventricular capture occurred in 23 of these discharges $(85.2 \%$ capture rate). A total of 32 non-transcardiac discharges were administered ventrally and capture was seen in only eight of these (25\% capture rate). Ventricular fibrillation (VF) was seen with two vectors, both of which were transcardiac. In the remaining animals, VT occurred postdischarge until sinus rhythm was regained spontaneously.

Conclusions: For most transcardiac vectors, Taser X26 caused immediate ventricular rhythm capture. This usually reverted spontaneously to sinus rhythm but potentially fatal VF was seen with two vectors. For some non-transcardiac vectors, capture was also seen but with a significantly $(p<0.0001)$ decreased incidence.

Key Words: Taser, Electromuscular incapacitation, Stun gun, Swine, Echocardiography, Dysrhythmia, Ventricular fibrillation.

J Trauma. 2008;65:1478-1487.
D ifferent types of stun guns or electromuscular incapacitation devices (EIDs) generate between 20,000 volts and 900,000 volts and can be discharged for more then 10 minutes continuously. In the United States alone, more

Submitted for publication December 27, 2008.

Accepted for publication August 26, 2008.

Copyright () 2008 by Lippincott Williams \& Wilkins

From the Cook County Trauma Unit (D.J.V., R.J.W., A.J.D., F.S., K.K.N., F.B., D.E.W., K.T.J., R.R.R.), Division of Cardiology (B.M.), John Stroger Hospital of Cook County, Chicago, Illinois; and Departments of General Surgery (D.J.V., R.J.W., A.J.D., K.K.N., F.B., D.E.W., K.T.J., R.R.R.), and Cardiology (B.M.), Rush University Medical Center, Chicago, Illinois.

Presented at the 21st Annual Meeting of the Eastern Association for the Surgery of Trauma, January 15-19, 2008, Jacksonville, Florida.

This article has an accompanying videoclip available as ArticlePlus material at www.jtrauma.com.

This study was supported by Trauma Department Research Fund (internally funded) and was funded solely by departmental research funds derived from the Cook County Trauma Unit. No financial interests in this or any other stun device manufacturer.

Address for reprints: Robert J. Walter, PhD, Department of Trauma, Rm 1300, Stroger Hospital of Cook County, 1900 West Polk St., Chicago, IL 60612; email: rwalter@cookcountytrauma.org.

DOI: 10.1097/TA.0b013e31818bc17a than 340,000 individuals have been exposed to discharges in field use from the most commonly used type of EID, the Taser. Unfortunately, in the United States and Canada, there have been more than 250 deaths in the past several years that have been temporally associated with the use of Tasers. ${ }^{1,2}$ Most of these custody-related deaths have been attributed to stimulant drug overdoses and intense agitation possibly resulting in hyperthermia, extreme acidosis, and cardiac failure. ${ }^{3}$ However, some have been directly attributed to the stun discharge. ${ }^{1,2,4}$ Worldwide, Tasers are currently used by over 11,000 law enforcement agencies and owned by more than 115,000 private citizens. ${ }^{5}$ The increasing numbers of fatalities linked to Taser use has intensified interest in EID safety and potential complications associated with their use, especially their ability to induce fatal ventricular dysrhythmias. ${ }^{6-9}$

Adding to the controversy over the safety profile of EIDs, is disagreement about the electrical output from these devices especially under resistive load and about what load is representative of human tissues. There is also disagreement about what model should be used for the study of EIDs in vitro or in vivo. ${ }^{6-8,10}$ Under no-load (zero resistance) conditions, the Taser X26 delivers DC pulses at $50 \mathrm{kV}$, with 140 
microseconds long pulses, a frequency of $19 \mathrm{~Hz}$, and output of $0.36 \mathrm{~J} /$ pulse. $^{5}$ In vivo such discharges cause severe pain, strong muscle contractions, and incapacitation of volitional movement. The manufacturer also states that, under a 400 ohm load, this device produces 90 microsecond pulses at $1200 \mathrm{~V}$ with a peak current of $3.5 \mathrm{~A}$ and $2.1 \mathrm{~mA}$ timeaveraged current. However, Webster ${ }^{11}$ and others ${ }^{10,12}$ assert that higher voltages and currents which exceed the human ventricular fibrillation (VF) threshold may be produced under physiologic or field conditions. In addition, computer or mathematical simulations of EID current distribution indicate that very little of the discharged current should penetrate to the heart and this low current density is insufficient to trigger VF. ${ }^{13-15}$ These conclusions are directly contradicted by swine studies showing that EID current does affect the heart ${ }^{16-18}$ and other modeling studies describing how VF may occur. ${ }^{19}$ Such contrasting opinions make the safety profile and physiologic effects of EIDs in humans difficult to deduce reliably.

First or second generation stun devices available before 1999 were much less powerful than present day EIDs, so conclusions derived from those studies may no longer apply. ${ }^{20-22}$ The peer-reviewed literature on fourth generation EIDs (such as the Taser X26) is rapidly emerging but the results are conflicting. Some studies, using a specially constructed Taser-like device (i.e., not a field issue Taser X26), have shown a large safety margin for the occurrence of VF in swine. $^{7,23,24}$ Similarly, neither ventricular capture nor dysrhythmias have been observed in healthy human volunteers exposed to brief ( $2-5$ seconds) Taser X26 discharges delivered primarily to the subject's dorsum. ${ }^{25-27}$ However, in swine models, Webster et al., ${ }^{28}$ Nanthakumar et al., ${ }^{16}$ and our group $^{17,18}$ have shown cardiac rhythm capture and even fatal dysrhythmias after Taser X26 discharges. Interestingly, recent data from pacemakers implanted in swine and in humans exposed to Taser discharges have clearly demonstrated cardiac dysrhythmias or capture during discharges. These dysrhythmias seemed to occur only during discharges having transcardiac electrical current paths (discharge vectors). ${ }^{29-31}$

We have studied the effects of Taser X26 discharges with various vectors in a well-characterized swine model. ${ }^{17,18,32,33}$ Our working hypothesis was that discharges from the Taser X26 could capture ventricular rhythm and that this capture was dependent on the discharge vector as determined by the anatomic location of the EID darts. We also hypothesized that particular vectors could lead to postdischarge cardiac effects including acute dysrhythmia or VF. Finally, we suggest guidelines for future EID studies that should improve data reproducibility.

\section{MATERIALS AND METHODS Animals and Groups}

Three- to 4-month-old Yorkshire pigs (Michael Fanning Farms, Howe, IN) weighing between $25 \mathrm{~kg}$ and $36 \mathrm{~kg}$ were used. The experimental group was comprised of four animals. This project was reviewed and approved by the IACUC for the Hektoen Institute for Medical Research, LLC. The musculoskeletal response to Taser discharges in anesthetized swine and conscious humans is very similar. ${ }^{7,34}$ The swine integumentary, musculoskeletal, and cardiovascular systems display numerous anatomic and physiologic similarities to humans, including the ratio of heart size to body mass, coronary arterial distribution, and susceptibility to $\mathrm{VF}^{35}$

All animals were anesthetized during each monitoring session using ketamine (Ketaset; Fort Dodge Animal Health, Fort Dodge, IA) and xylazine (Anased; Lloyd, Shenandoah, IA), and respiratory secretions were inhibited using glycopyrollate (Robinul; Fort Dodge Animal Health, Fort Dodge, IA). Ketamine/xylazine/glycopyrollate $(30 / 3 / 0.01 \mathrm{mg} / \mathrm{kg}$ ) were administered intramuscularly for sedation, and then ketamine and xylazine $(5.6 / 0.8 \mathrm{mg} / \mathrm{mL})$ in sterile saline were instilled intravenously using an infusion pump (Flogard 6200; Travenol, Deerfield, IL) through an ear vein cannula at $3 \mathrm{~mL} \cdot \mathrm{h}^{-1} \cdot \mathrm{kg}^{-1}$ $(16.8 / 2.4 \mathrm{mg} / \mathrm{kg})$. Animals were intubated using cuffed endotracheal tubes (5.0 $\mathrm{mm}$ to $6.5 \mathrm{~mm}$, Rusch; Kernen, Germany) after anesthetizing the larynx with 0.25 to $1.0 \mathrm{~mL}$ of sprayed $20 \%$ benzocaine (Hurricaine; Beutlich Pharm., Waukegan, IL). Breathing was controlled at 15 breaths per minute with a tidal volume of $10 \mathrm{~mL} / \mathrm{kg}$ and minute volume of $150 \mathrm{~mL} / \mathrm{kg}$. Animals were maintained in dorsal recumbence for all electrical discharges and monitoring procedures. Inhaled halothane, isoflurane, and barbiturate anesthesia were not used in favor of IV ketamine/xylazine to avoid inadvertent effects from the inhalation agents related to electroporation. ${ }^{36,37}$

\section{Test Device}

An unmodified, police-issue Taser X26 was used to elicit EMI. Because it is illegal for civilians to possess the Taser X26 in the greater Chicago area, the discharges were delivered by a member of the local law enforcement community trained in Taser use. Taser lithium $6 \mathrm{~V}$ digital power magazines (DPM) were used as the power source for all discharges. DPM charge state was monitored before and after each discharge, and at no time was a DPM used with a charge state less than $60 \%$.

\section{Experimental Set-Up and EMI Discharge}

While in dorsal recumbence, all four limbs of the animal were loosely restrained to the table. The Taser cartridge was fired into a towel and the darts were disentangled from the cloth without disrupting any of the fine wires, insulation, or connections. A series of different Taser dart arrangements was then examined. The Taser darts were arranged in transcardiac (a straight line connecting the darts would cross the surface projection of the heart) or non-transcardiac vectors (see Fig. 1). During discharge, the Taser X26 emits current primarily from one dart and the position of this current emitting dart was noted. Just before Taser discharge, $2 \mathrm{mg} / \mathrm{kg}$ succinylcholine ( $\mathrm{SCh}$ ) (Sandoz, Broomfield, $\mathrm{CO}$ ) was given intravenously. When fasciculations ended, the Taser discharges were started. SCh was used for two reasons. It limited 


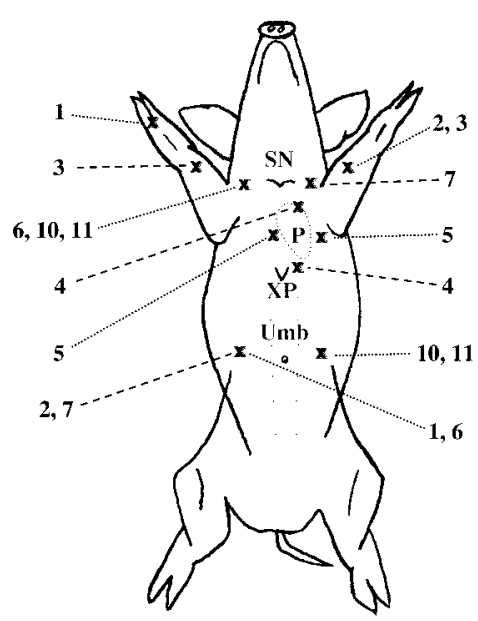

VENTRAI,

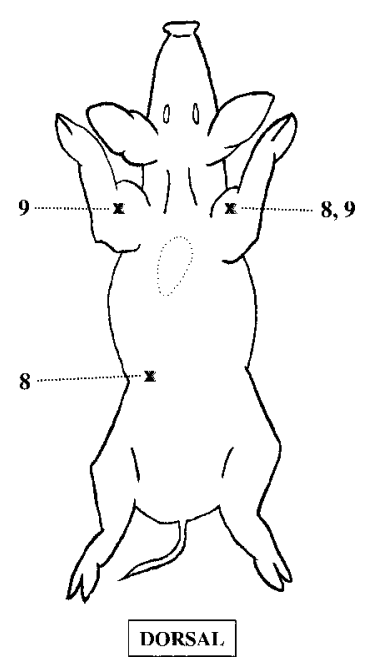

DORSAI
Fig. 1. Dart placement on the dorsal and ventral body surfaces of swine. Pairs of dart locations are indicated on these sketches for each vector (1,1 through 11,11). Anatomic landmarks are shown sternal notch (SN), xiphoid process (XP), umbilicus (Umb), and descriptions for each dart location relative to these landmarks are given in Table 1. The cardiac silhouette is shown as a dotted line and the point of maximum intensity $(\mathrm{P})$ is shown. Darts were inserted perpendicular to the skin to their maximum depth $(12 \mathrm{~mm})$ such that the dart tip was located in subcutaneous tissue. For vectors 10 and 11, darts did not penetrate the skin. Instead, they were taped to the skin surface (vector 10) or held $1 / 2$ inch above the skin using insulating blocks (vector 11).

the metabolic effects (i.e. acidosis) of discharges so that direct effects on cardiac rhythm could be isolated from the metabolic effects. Our previous studies ${ }^{17,18}$ showed that lengthy Taser discharges caused significant acidosis, but that this could be largely prevented by using SCh without altering the cardiac effects. Also, SCh paralyzed skeletal musculature making echocardiography imaging possible during the Taser discharges by preventing the violent shaking of the animal's torso otherwise induced by the discharges.

Ten second discharges were administered for each vector and for reverse polarity with each vector. To obtain reverse polarity, the darts were not moved but the cartridge was removed from the gun, rotated 180 degrees, and then reattached so that another 10 seconds discharge could be administered. Thus, the nonemitting dart became the current emitting dart and the direction of current flow in the animal tissues during the discharge was reversed when compared with the prior discharge. Fifteen to 60 second rests were allowed between discharges. When defibrillation was needed $(250 \mathrm{~J}), 15$ minutes were allowed before resuming tests. The order of discharges was varied only to a small extent. After VF was observed with vector 5 in the first animal studied, this vector was deferred until the end of the subsequent experiments so that the possible use of defibrillation would not affect the results with other vectors. Webster and coworkers. ${ }^{38}$ have shown that episodes of VF and defibrillation make subsequent episodes somewhat more likely.

ECG and echocardiography were used to assess cardiac rhythm before, during, and after each discharge. Four animals were exposed to a total of 67 Taser discharges with different vectors, current emitting dart locations, and current directions. All vectors and polarities were repeated at least twice. For most vectors studied, the darts were inserted perpendicular to the skin and to their full depth $(12 \mathrm{~mm})$. In one animal, the right chest to left abdomen vector (10 and 11 in Fig. 1) which had yielded a $100 \%$ capture rate and sometimes VF in previous studies ${ }^{16-18}$ was used. However, instead of inserting the darts into the skin, both darts were either taped to the skin surface (nonpenetrating, vector 10 ) or elevated $1 / 2$ inch above the skin using insulating foam blocks (vector 11). This latter arrangement resulted in arcing through the air between the dart tips and the skin surface during the discharge.

\section{Cardiac Rhythm and Echocardiography}

Cardiac rhythm was monitored continuously during anesthesia using a 5-lead ECG (Datex instruments, Helsinki, Finland). ECGs were also recorded during each discharge. ECG tracings showed normal sinus rhythm before the discharges but because of the electrical and mechanical background noise caused by the Taser discharge, ECGs performed during the discharge were unreadable. Immediately after the discharges, ECGs were again usable and showed either rapid re-establishment of sinus rhythm or abnormal rhythms. Varying periods of ventricular tachycardia (VT) were seen followed by either normal sinus rhythm or VF.

To adequately assess the rhythm and function of the myocardium, echocardiography was performed using a GE LOGIQ7 with a $3 \mathrm{MHz}$ probe. Echo images were first obtained predischarge to establish a baseline for each animal from a cross-sectional view of the left ventricle. Echocardiography was then continued during and after each Taser discharge to assess, in real time, any changes that occurred in left ventricular rhythm. Digital video recordings of each echocardiograph were reviewed and analyzed using Studio QuickStart software (v 9.3, Pinnacle, Bakersfield, CA).

The multiple, standard echo views that are used in humans to calculate cardiac output or ejection fraction could not be obtained in swine under the conditions used here, so a single (parasternal short axis) window was used. This was necessitated by anatomic differences in swine, such as the closeness of the rib spacing, the prominence of the sternum, and the rotation of the long axis of the heart to a more anteroposterior orientation ${ }^{39,40}$ making it difficult to obtain more than one unobstructed view of the left ventricle (LV). Further, the brief time period available during the discharges (10 seconds) precluded repositioning the transducer to capture multiple views, and this precluded quantitative estimations of cardiac function. Cardiac rhythm capture, where the normal electrical rhythm of the heart is overridden and its mechanical function disrupted as a result of rapid ventricular 
contractions consistent with VT or ventricular flutter, was readily discerned.

Animals were humanely killed according to AVMA standards at the completion of the study by switching the anesthesia to $5 \%$ inhaled isoflurane and injecting $3 \mathrm{~mol} / \mathrm{L}$ $\mathrm{KCl}$ into the heart.

\section{Data Analysis}

Two-sided Fisher's exact tests were used to compare groups of nonparametric data points from $2 \times 2$ contingency tables. Trends were evaluated using linear regression with InStat 3.0 (GraphPad, San Diego, CA).

\section{RESULTS \\ Capture of Ventricular Rhythm was Dependent on Discharge Vector}

Cardiac dysrhythmia only was seen in 17\% (10 of 59) of ventral discharges and capture was seen in $52.5 \%$ (31 of 59) of all discharges that were administered to the ventral surface of the animals. For the latter, echocardiography showed capture of the ventricular rhythm with rapid ventricular contractions consistent with VT or ventricular flutter during the entire discharge unless otherwise indicated (Fig. 2; Table 1 [for the entire video, see: http://cookcountytrauma1.googlepages. com/home]). Capture occurred immediately after the discharge started and continued until the discharge terminated. In all surviving animals, sinus rhythm was regained immediately or within several seconds after the termination of the discharge.

Ventricular rhythm was captured in 23 of 27 ventral transcardiac discharges ( $85.2 \%$ capture rate, see Table 2). This was a significantly higher capture rate than that seen with ventral non-transcardiac discharges $(p<0.0001)$. Alternatively, a total of 40 Taser discharges were administered such that the heart was not interposed between the darts and capture was seen in only eight of these discharges $(20.0 \%$ capture rate; $p<0.0001$ for all transcardiac versus all nontranscardiac). For non-transcardiac vectors, there were eight instances of capture. All of these were transdiaphragmatic and there was no statistically significant association seen between transdiaphragmatic vectors and ventricular capture $(p=0.0815)$.

Two vectors on the animal dorsum were studied (vectors 8 and 9). These included vectors between the right posterior shoulder and left posterior superior iliac spine and between the acromial processes of the left and right scapulae (see Fig. 1). These vectors were used because they are analogous to ventral vectors that always showed capture and occasionally resulted in VF. ${ }^{17,18}$ Dorsal vectors are of additional interest because they are often employed in Taser training exercises by law enforcement agencies. None of the eight dorsal discharges with these two vectors resulted in capture or any other observable effect on cardiac activity as seen by echo.

\section{Echo at End Diastole for Vector \#5}

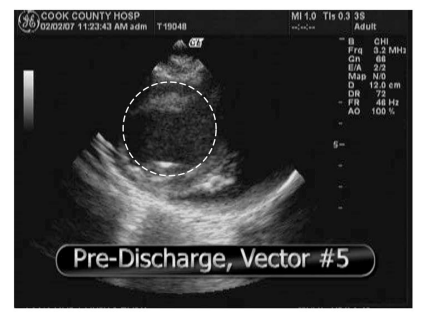

Pre-Discharge

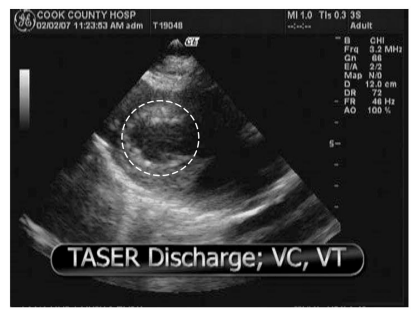

Mid-Discharge

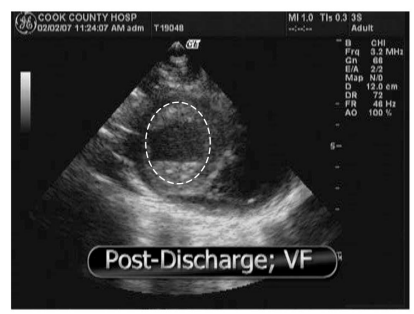

Post-Discharge
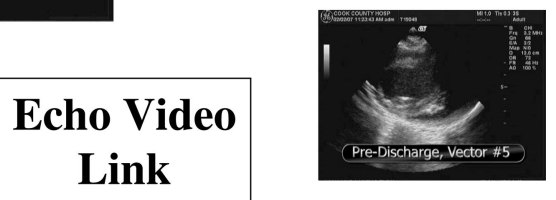

Fig. 2. Echocardiograph frame grabs showing the left ventricle (LV) at end diastole in the pre-discharge (top), mid-discharge (middle), and postdischarge periods (bottom). The dashed white circles or ovals show the outline of the LV chamber during each experimental period. A link to the video from which these frames were obtained is shown in the lower right corner. This video is in windows media video (WMV) format and can be viewed using Winamp (Nullsoft, Sedona, AZ) or another compatible video player (see supplemental video clip, ArticlePlus, www.jtrauma.com). This video, edited only to reduce file size by reducing the resolution, shows LV rhythm during a 30 second continuous sequence of pre-discharge, Taser discharge, and post-discharge. Normal LV rhythm is seen in the pre-discharge period, ventricular capture (VC) is seen during the Taser discharge along vector 5, and a rhythm consistent with VF is seen in the post-discharge period.

\section{Some Transcardiac Vectors did not Produce Ventricular Capture}

Interestingly, there were two transcardiac discharge vectors which did not result in capture of ventricular rhythm. For one of these, both darts were taped to the skin surface, not penetrating the epidermis, and the current emitting dart was on the abdomen (vector 10 left abdomen). Some cardiac dysrhythmia was observed with this vector but capture with a rapid rhythm consistent with VT/ventricular flutter was not seen. With nonpenetrating, taped darts in this arrangement, 


\section{Table 1 Ventricular Capture With Different Vectors}

\begin{tabular}{|c|c|c|c|c|c|c|c|c|}
\hline \multirow{2}{*}{$\begin{array}{l}\text { Vector } \\
\text { Number }\end{array}$} & \multicolumn{3}{|c|}{ Vector Used } & \multicolumn{4}{|c|}{ Rhythm Seen in Each Animal Studied } & \multirow{2}{*}{$\begin{array}{l}\text { Capture } \\
\text { Rate }\end{array}$} \\
\hline & $\begin{array}{l}\text { Dorsal/ } \\
\text { Ventral }\end{array}$ & Description & Transcardiac & $\begin{array}{c}A \\
26 \mathrm{~kg}\end{array}$ & $\begin{array}{c}\mathrm{B} \\
25 \mathrm{~kg}\end{array}$ & $\underset{36 \mathrm{~kg}}{\mathrm{C}}$ & $\begin{array}{c}D \\
30 \mathrm{~kg}\end{array}$ & \\
\hline 1 & Ventral & $\mathrm{R}$ hoof/R abdomen & No & Y...Dys & Dys & Dys & $\mathrm{N}$ & $2 / 8=25 \%$ \\
\hline 3 & Ventral & $R$ foreleg/L foreleg & No & $\mathrm{N}$ & $\mathrm{N}$ & $\mathrm{N}$ & $\mathrm{N}$ & $0 / 8=0 \%$ \\
\hline 4 & Ventral & $5 \mathrm{~cm}$ sup $/ 5 \mathrm{~cm}$ inf to $\mathrm{PMI}$ & Yes & & $\mathrm{Y}$ & $\mathrm{Y}$ & $\mathrm{Y}$ & $6 / 6=100 \%$ \\
\hline 5 & Ventral & $5 \mathrm{~cm} \mathrm{R} / 5 \mathrm{~cm} \mathrm{~L} \mathrm{of} \mathrm{PMl}$ & Yes & & Y...VF & $\begin{array}{l}Y \ldots V F \\
Y\end{array}$ & $\mathrm{Y}$ & $\begin{array}{l}2 / 9=22 \% \\
9 / 9=100 \%\end{array}$ \\
\hline 6 & Ventral & $\mathrm{R}$ chest/R abdomen & No & & & $\begin{array}{l}\text { Dys } \\
\text { Y...Dys }\end{array}$ & $\mathrm{Y}$ & $6 / 8=75 \%$ \\
\hline 7 & Ventral & L chest/R abdomen & Yes & & & Dys & $\mathrm{Y}$ & $2 / 4=50 \%$ \\
\hline 8 & Dorsal & R shoulder/L PSIS & No & & & $\mathrm{N}$ & $\mathrm{N}$ & $0 / 4=0 \%$ \\
\hline 9 & Dorsal & R shoulder/L shoulder & No & & & $\mathrm{N}$ & $\mathrm{N}$ & $0 / 4=0 \%$ \\
\hline 10 & Ventral & $\mathrm{R}$ chest/L abdomen & Yes & & & & Dys & $0 / 2=0 \%$ \\
\hline
\end{tabular}

PMI indicates point of maximum impulse; Dys, dysrhythmia; Y, capture; N, no capture; VF, ventricular fibrillation.

For further details, see: http://cookcountytrauma1.googlepages.com/home.

Table 2 Ventricular Capture Summary for All Vectors Used

\begin{tabular}{|c|c|c|c|c|}
\hline \multirow{2}{*}{ Vectors } & \multicolumn{2}{|c|}{ Transcardiac $^{*}$} & \multicolumn{2}{|c|}{ Non-Transcardiac* } \\
\hline & Ventral $^{\dagger}$ & Dorsal & Ventral & Dorsal \\
\hline Transdiaphragmatic $^{\ddagger}$ & 8 of 12 capture ${ }^{\S \|}$ & 0 of 0 capture & 8 of 24 capture $^{\S \uparrow}$ & 0 of 4 capture \\
\hline
\end{tabular}

Using Fisher's exact test tests with $2 \times 2$ contingency tables:

${ }^{*} p<0.0001$ for all transcardiac vs. all non-transcardiac vectors.

${ }^{+} p<0.0001$ for ventral transcardiac vs. ventral non-transcardiac vectors.

${ }^{\ddagger} p=0.225$ for all transdiaphragmatic vs. all non-transdiaphragmatic vectors.

$\S p=0.1814$ for ventral transdiaphragmatic vs. ventral non-transdiaphragmatic vectors.

$\| p=0.0282$ for ventral transcardiac vectors; transdiaphragmatic vs. non-transdiaphragmatic vectors.

" $p=0.0815$ for non-transcardiac vectors; ventral transdiaphragmatic vs. ventral non-transdiaphragmatic vectors.

capture was seen only when the emitting dart was on the chest (vector 10 right chest). In the second case, where a transcardiac vector was used without capture (vector 7), one dart was placed subcutaneously in the left chest and the other subcutaneously in the right abdomen. This configuration represented a left-right mirror image of the vector used in our previous Taser studies, where $100 \%$ capture had been seen. ${ }^{17,18}$ Two animals were studied using this mirror image arrangement (vector 7). For both, capture was seen with the current emitting dart in the chest position but only dysrhythmia was seen with the emitting dart in the abdomen position.

\section{Ventricular Capture did not Require Skin Penetration of Darts}

Interestingly, for two of the vectors studied (vectors 10 and 11), the darts did not penetrate the skin but a $75 \%$ capture rate was nonetheless observed. For vector 10, the darts were both laid flat on and taped to the skin with one dart on the right chest and the other over the left upper abdomen (see Fig. 1) in an arrangement previously shown to result in $100 \%$ capture. ${ }^{17,18}$ When the darts were taped to the skin, a $50 \%$ capture rate was seen. When this vector was repeated with the darts held away from the skin by insulating foam blocks, a $100 \%$ rate of capture was seen.

\section{Ventricular Fibrillation was Induced in Two Animals}

VF was seen twice in this study. In both cases, the Taser darts were arrayed transversely across the chest and centered during the point of maximum impulse (PMI) across the heart (see Fig. 1 and Table 1, vector 5). VF occurred with this vector when current flowed right to left and also when current flowed left to right. With this discharge vector, a total of nine discharges were administered to three animals with capture occurring in all cases (9 of 9) and VF resulting from two of the discharges ( $22 \%$ frequency of VF). 


\section{DISCUSSION}

Case reports, autopsies, and retrospective analyses have suggested that Taser discharges may be associated with fatal dysrhythmias in humans, although the frequency of this complication is extremely low. ${ }^{1,6-9,41} \mathrm{We}$ showed in previous swine studies using echocardiography and ECG that Taser discharges administered with a right chest to left abdomen transcardiac vector ${ }^{34}$ had dramatic effects on myocardial mechanics. This included rhythm capture with diminished ejection fraction and conversion to VT that sometimes degraded to VF. These effects were independent of body mass and systemic acidosis. ${ }^{17,18}$ The present study confirms that the cardiac effects of Taser X26 discharges are highly dependent on the discharge vector. This extends the findings of Nanthakumar et al. ${ }^{16}$ who showed that discharges from an unmodified Taser X26 captured ventricular rhythm in swine more often when the discharge was across the thorax (98\% capture) than across the abdomen ( $0 \%$ capture). ${ }^{16}$

Using darts arrayed across the dorsal surface of the animal, we saw neither capture nor dysrhythmia. Dorsal or posterior vectors are commonly used on human volunteers during law enforcement training exercises and, despite thousands of such exposures, no cardiac arrests have been reported. Human studies using such vectors have found no postdischarge dysrhythmias on ECG. ${ }^{25,42}$ The data presented here confirm that dorsal vectors do not induce cardiac dysrhythmias. However, this conclusion cannot be generalized to include ventral thoracic vectors, which have a significant likelihood of eliciting cardiac effects.

It has been postulated that discharges administered closer to the heart are most likely to affect the cardiac rhythm. However, high rates of ventricular capture were seen here and elsewhere ${ }^{17,18}$ even when the darts were quite distant from the heart. Further, it was not necessary for the darts to penetrate or even to be in contact with the skin to elicit capture (vectors 10 and 11). The studies of Webster et al. ${ }^{28}$ and $\mathrm{Wu}$ et al. ${ }^{43}$ have carefully documented the relationship between the Taser dart-to-heart distance and the occurrence of VF in swine. They found that dart-to-heart distances $>20 \mathrm{~mm}$ did not result in VF whereas distances $\leq 20 \mathrm{~mm}$ often did. In the present study, the skin surface-to-heart distance at the PMI as measured by echo for vector 5 was $25 \mathrm{~mm}$. The darts penetrated $12 \mathrm{~mm}$ into the subcutaneous tissue, so the dart-toheart distance was probably within the $20 \mathrm{~mm}$ range shown to trigger VF. However, such dart proximity to the heart does not account for instances of VF seen in our previous studies, ${ }^{17,18}$ where the dart-to-heart distances for the each dart were $>90 \mathrm{~mm}$.

Such data suggest that the global effects of stun devices on the skeletal musculature do not result solely from mass action of these currents through a volume conductor that attenuates the current as the distance from the source increases. In addition, nerves in the vicinity of the emitting dart are probably used to rapidly disseminate the powerful dis- charges throughout the body. ${ }^{44-46}$ Thus, effects on the heart may be mediated by direct action on the heart muscle as per Webster's findings ${ }^{28,43}$ or by indirect but overwhelming stimulation carried by the cardiac innervation. This hypothesis is readily testable in swine using pharmacologic agents (e.g., peripheral sympatholytics or ganglionic blockers), application of local anesthetics, or surgical transection to interrupt nerve transmission.

Using a custom-built Taser-like device, others ${ }^{7}$ have reported that the threshold for VF was directly proportional to body mass for animals ranging from $30 \mathrm{~kg}$ to $117 \mathrm{~kg}$. The output power for the device used in that study could be adjusted, unlike any commercially-available Taser. That study reported that VF could be induced in swine only when the output power was increased 15 -fold above normal in a 30 $\mathrm{kg}$ animal. In another study using a similar Taser-like device, at least four times the output of a standard Taser X26 discharge was required to induce ventricular capture in swine averaging $34 \mathrm{~kg}$ in mass. ${ }^{23}$ Previously, we reported ${ }^{17,18}$ that three episodes of VF (out of 16 animals) occurred with lengthy (two 40 seconds) Taser discharges and had hypothesized that the observed VF may have occurred because of the prolonged duration of those discharges. The present study showed that VF may occur even with much briefer 10 second discharges of a standard Taser X26.

$\mathrm{SCh}$, a depolarizing muscle relaxant, can by itself cause bradycardia and junctional myocardial rhythms, ${ }^{47}$ so we must also consider the possibility that $\mathrm{SCh}$ contributed to the dysrhythmias seen here. However, bradycardia was not seen in response to SCh injection in experimental or control animals. Further, we have reported identical dysrhythmias in swine exposed to Taser X26 discharges in the absence of SCh. ${ }^{17}$ The results of this study agree with other published swine studies $^{16,28,30,43}$ that have employed standard law enforcement-grade Taser X26 devices showing that discharges can alter cardiac rhythm. All of these findings are at variance with those obtained using custom-built Taser-like devices. ${ }^{7,23}$

There are several potential limitations to this study. First, anesthetized animals were used for ethical reasons. This precluded pain perception, which is one of the two principal effects of Taser discharges in conscious humans. Second, the animal numbers were small but the cardiac effects were highly reproducible. Third, resting animals were used whereas Tasers are generally used in the field to subdue highly agitated individuals who are often under the influence of stimulatory drugs. Under those conditions, the effects of Taser discharges may differ from those seen here. Fourth, some differences exist between swine and humans in the cardiac conduction system, ${ }^{35,48}$ thoracic geometry, and the rotation of the heart within the thorax which may affect the thresholds for arrhythmia or VF in swine. Despite these differences, swine are an effective model for ventricular arrhythmia and pacemaker testing ${ }^{40,49-51}$ and are the primary animal model for the study of EIDs. ${ }^{7,11,16,17,23,28,30,34,43}$ Finally, the animals studied here had no cardiac abnormalities so the effects of 
preexisting structural heart disease, as might occur in humans subjected to Taser discharges, was not assessed.

In this swine model, transcardiac discharge vectors on the ventral surface very often ( $85.2 \%$ of the time) produced ventricular capture, which was seen as high-rate VT. This capture usually reverted spontaneously to sinus rhythm postdischarge but in two instances degenerated into VF. Because of the use of $\mathrm{SCh}$, the extreme acid-base disturbances previously seen after lengthy Taser discharges ${ }^{17,34}$ were absent showing that cardiac dysrhythmias are independent of systemic acidosis. Because these aberrant rhythms usually resolved within seconds after terminating the discharge, such dysrhythmias would go undetected if they occurred in humans exposed to Taser discharges in the field. In human volunteers, several groups have reported finding no significant ECG abnormalities aside from mild tachycardia after Taser X26 discharges. ${ }^{25,42,52}$ Electrical noise also interfered with ECGs obtained during discharges in those studies so ventricular capture, if it occurred, would have been obscured. In addition, the discharge vectors used in those human studies differed from the transcardiac vectors that captured ventricular rhythm here. As a result, those studies may have missed important alterations in cardiac activity that occur only during transcardiac discharges and may not have measurable after-effects.

Based upon the results of this and related studies, we have several recommendations:

1. The discharge vector used in animal or human studies should be carefully documented. The vector will directly affect the results. Non-transcardiac or dorsal vectors are unlikely to have cardiac effects.

2. Future studies should focus on the use of unmodified police-issue Tasers. Results from studies employing "custom-built devices" do not correlate with those from studies using unmodified Tasers. ${ }^{7,16-18,23,24,38}$

3. High-capacity (lithium) batteries used for the Taser should be fully charged or no less than $60 \%$ charged at the conclusion of any discharge. At a low-charge state, EID output may be affected. The battery type and charge state should be documented and any alternative power sources specified.

4. In the field, Taser or other EID darts may sometimes be arrayed with a ventral transcardiac vector. If our data can be translated to humans, then ventricular rhythm may be captured and postdischarge dysrhythmias or VF may occur. Such transcardiac vectors should be avoided when possible and the potential for deterioration of the cardiac rhythm to VF in the field should be considered. Tasers are useful tools for law enforcement, but EID users should be trained to recognize the possible cardiac effects and be prepared to use automated external defibrillators and cardiopulmonary resuscitation maneuvers when needed.

5. Human studies using transcardiac vectors in conjunction with echo during the discharge would be of great interest. However, cardiac effects seen in animal models suggest that the risk of serious injury in such studies is very high.

\section{ACKNOWLEDGMENTS}

We thank the staff of the Animal Facility for their assistance, the Des Plaines Illinois Police Department, and the Northern Illinois Police Alarm System (NIPAS) for providing essential equipment.

\section{REFERENCES}

1. Amnesty International. United States of America Excessive and Lethal Force? Amnesty International's concerns about deaths and ill-treatment involving police use of tasers. Available at: http:// www.amnestyusa.org/countries/usa/Taser_report.pdf. Published 1130-2004. Accessed October 2, 2007.

2. Ward, C. Taser death update. Available at: http://www.cameronward. com/tasers/. Published 819322-2007. Accessed October 2, 2007.

3. Bozeman WP. Withdrawal of taser electroshock devices: too much, too soon. Ann Emerg Med. 2005;46:300-301.

4. Amnesty International. Canada: Inappropriate and excessive use of tasers. Available at: http://www.amnesty.org/en/alfresco_asset/ 6c6342e0-a2bf-11dc-8d74-6f45f39984e5/amr200022007en.pdf. Published 5-23-2007. Accessed January 3, 2008.

5. TASER International Website. Available at: www.taser.com. Published 3-30-2008. Accessed March 30, 2008.

6. Bleetman A, Steyn R. The advanced Taser: a medical review. Available at: http://www.taser.com/research/Science/Documents/ Bleetman\%20TASER\%20safety.pdf, 1-30. Published 4-27-2003. TASER International. Accessed January 3, 2008.

7. McDaniel WC, Stratbucker RA, Nerheim M, Brewer JE. Cardiac safety of neuromuscular incapacitating defensive devices. Pacing Clin Electrophysiol. 2005;28(Suppl 1):S284-S287.

8. Bleetman A, Steyn R, Lee C. Introduction of the Taser into British policing. Implications for UK emergency departments: an overview of electronic weaponry. Emerg Med J. 2004;21:136-140.

9. Roy OZ, Podgorski AS. Tests on a shocking device-the stun gun. Med Biol Eng Comput. 1989;27:445-448.

10. Ruggieri JA. Forensic engineering analysis of electro-shock weapon safety. J Natl Acad Foren Engin. 2005;22:1-34.

11. Webster JG. Electromuscular incapacitating devices. IFBME Proceedings. 2005;9:150-151.

12. Loy E. Taser energy beyond specs, jury hears. canoe network. Available at: http://vancouver.24hrs.ca/News/2007/05/25/pf4206571.html. Published May 25, 2007.

13. Panescu D. TASER ECD distribution. Available at: http:// www.taser.com/research/Science/Pages/TASERECDDistrubition. aspx. Published September 13, 2007.

14. Holden SJ, Sheridan RD, Coffey TJ, Scaramuzza RA, Diamantopoulos P. Electromagnetic modelling of current flow in the heart from TASER devices and the risk of cardiac dysrhythmias. Phys Med Biol. 2007; 52:7193-7209.

15. Ideker RE, Dosdall DJ. Can the direct cardiac effects of the electric pulses generated by the TASER X26 cause immediate or delayed sudden cardiac arrest in normal adults? Am J Forensic Med Pathol. 2007;28:195-201.

16. Nanthakumar K, Billingsley IM, Masse S, et al. Cardiac electrophysiological consequences of neuromuscular incapacitating device discharges. J Am Coll Cardiol. 2006;48:798-804.

17. Dennis AJ, Valentino DJ, Walter RJ, et al. Acute effects of TASER ${ }^{\circledR}$ X26 discharges in a swine model. J Trauma. 2007;63:581-590.

18. Walter RJ, Dennis AJ, Valentino DJ, et al. TASER X26 discharges in swine produce potentially fatal ventricular arrhythmias. Acad Emerg Med. 2008;15:66-73. 
19. Sun, H. Models of ventricular fibrillation probability and neuromuscular stimulation after TASER use in humans. Available at: http://ecow.engr.wisc.edu/cgi-bin/getbig/bme/762/webster/sunthesis-01-21-07.pdf. Published 5-1-2008. University of Wisconsin. Accessed May 1, 2008.

20. Ordog GJ, Wasserberger J, Schlater T, Balasubramaniam S. Electronic gun (Taser) injuries. Ann Emerg Med. 1987;16:73-78.

21. O'Brien DJ. Electronic weaponry-a question of safety. Ann Emerg Med. 1991;20:583-587.

22. Koscove EM. The Taser weapon: a new emergency medicine problem. Ann Emerg Med. 1985;14:1205-1208.

23. Lakkireddy D, Wallick D, Ryschon K, et al. Effects of cocaine intoxication on the threshold for stun gun induction of ventricular fibrillation. J Am Coll Cardiol. 2006;48:805-811.

24. Lakkireddy D, Wallick D, Verma A, et al. Cardiac effects of electrical stun guns: does position of barbs contact make a difference? Pacing Clin Electrophysiol. 2008;31:398-408.

25. Ho JD, Miner JR, Lakkireddy D, Bultman LL, Heegaard WG. Cardiovascular and physiologic effects of conducted electrical weapon discharge in resting adults. Acad Emerg Med. 2006;13:589-595.

26. Vilke GM, Sloane CM, Bouton KD, et al. Physiological effects of a conducted electrical weapon on human subjects. Ann Emerg Med. 2007;50:569-575.

27. Levine SD, Sloane CM, Chan TC, Dunford JV, Vilke GM. Cardiac monitoring of human subjects exposed to the taser. J Emerg Med. 2007;33:113-117.

28. Webster JG, Will JA, Sun H, et al. Can TASERS directly cause ventricular fibrillation. IFBME Proc. 2006;14:3307-3310.

29. Cao M, Shinbane JS, Gillberg JM, Saxon LA. Taser-induced rapid ventricular myocardial capture demonstrated by pacemaker intracardiac electrograms. J Cardiovasc Electrophysiol. 2007; 18:876-879.

30. Calton R, Cameron D, Masse S, Nanthakumar K. Duration of discharge of neuromuscular incapacitating device and inappropriate implantable cardioverter-defibrillator detections. Circulation. 2007; 115:472-474.

31. Lakkireddy D, Khasnis A, Antenacci J, et al. Do electrical stun guns (TASER-X26) affect the functional integrity of implantable pacemakers and defibrillators? Europace. 2007;9:551-556.

32. Valentino DJ, Walter RJ, Nagy K, et al. Repeated thoracic discharges from a stun device. J Trauma. 2007;62:1134-1142.

33. Valentino DJ, Walter RJ, Dennis AJ, et al. Neuromuscular effects of stun device discharges. J Surg Res. 2007;143:78-87.

34. Jauchem JR, Sherry CJ, Fines DA, Cook MC. Acidosis, lactate, electrolytes, muscle enzymes, and other factors in the blood of Sus scrofa following repeated TASER((R)) exposures. Forensic Sci Int. 2006;161:20-30.

35. Swindle MM. Surgery, Anesthesia, and Experimental Techniques in Swine. Ames: Iowa State University Press; 1998.

36. Lee RC. Injury by electrical forces: pathophysiology, manifestations, and therapy. Curr Probl Surg. 1997;34:677-764.

37. Lee RC, Zhang D, Hannig J. Biophysical injury mechanisms in electrical shock trauma. Annu Rev Biomed Eng. 2000;2:477-509.

38. Wu J-Y, Sun H, O'Rourke AP, Huebner S, Rahko PS, Will JA, Webster JG. Taser dart-to-heart distance that causes ventricular fibrillation in pigs. IEEE Trans Biomed Eng. 2007;54:503-508.

39. Lee MY, Lee SH, Lee SG, et al. Comparative analysis of heart functions in micropigs and conventional pigs using echocardiography and radiography. J Vet Sci. 2007;8:7-14.

40. Crick SJ, Sheppard MN, Ho SY, Gebstein L, Anderson RH. Anatomy of the pig heart: comparisons with normal human cardiac structure. J Anat. 1998;193(Pt 1):105-119.

41. Schlosberg M, Levin J, Batliwalla S, et al. Stun gun fallacy: How the lack of Taser regulation endangers lives. Available at: http://www. aclunc.org/issues/criminal_justice/police_practices/special_report_stun_ gun_fallacy.shtml. Accessed July 14, 2007.

42. Vilke GM, Sloane C, Levine S, Neuman T, Castillo E, Chan TC. Twelve-lead electrocardiogram monitoring of subjects before and after voluntary exposure to the Taser X26. Am J Emerg Med. 2008; 26:1-4.

43. Wu J-Y, Sun H, O'Rourke AP, Webster JG. Taser dart-to-heart distance that causes ventricular fibrillation in pigs. Available at: http://www.engr. wisc.edu/bme/faculty/webster_john/EB2006Final.pdf. Published 2006. Accessed October 2, 2007.

44. Sun H, Webster JG. Estimating neuromuscular stimulation within the human torso with Taser(R) stimulus. Phys Med Biol. 2007;52:64016411

45. Reilly JP. Mechanisms of electrostimulation: application to electromagnetic field exposure standards at frequencies below 100 kHz. Applied Bioelectricity: From Electrical Stimulation to Electropathology. New York: Springer; 1998.

46. Reilly JP. Mechanisms of electrostimulation: application to electromagnetic field exposure standards at frequencies below 100 kHz. In: Chadwick P, Gabriel CH, eds. EMF Dosimetry Handbook. Texas: USAF, AFSC, Brooks AF; 2003. Available at: www.emfdosimetry.org

47. Ezekiel MR. Pharmacology. Handbook of Anesthesiology. CA: Current Clinical Strategies Publ.;2005:68-71.

48. Bharati S, Levine M, Huang SK, et al. The conduction system of the swine heart. Chest. 1991;100:207-212.

49. Brownlee RR, Swindle MM, Bertolet R, Neff P. Toward optimizing a preshaped catheter and system parameters to achieve single lead DDD pacing. Pacing Clin Electrophysiol. 1997;20:1354-1358.

50. Smith AC, Knick B, Gillette PC, Swindle MM. A technique for conducting noninvasive cardiac electrophysiology studies in conscious swine. J Invest Surg. 1997;10:25-29.

51. Verdouw PD, Hartog JM, Saxena PR, Hugenholtz PG. Systemic and regional hemodynamic, antiarrhythmic and antiischemic effects of bevantolol in anesthetized pigs. Am J Cardiol. 1986;58:8E-16E.

52. Levine SD, Sloane C, Chan T, Donford JV, Vilke JM. Cardiac monitoring of human subjects exposed to the Taser. Acad Emerg Med. 2006;13:S47.

\section{DISCUSSION}

Dr. Angela Earley (Chesapeake, Virginia): The TASER is a trademarked, electro-muscular incapacitation device developed in 1969 and was coined as an acronym for the Thomas A. Swift Electronic Rifle. The use of the electronic stun gun has increased dramatically in the last decade, as it has been marketed as a less than lethal force weapon to be used by law enforcement officers to subdue belligerent and dangerous subjects.

It is currently reported that over 11,000 law enforcement agencies nationwide are employing this modality during escalation of force. However, their use and safety has come under scrutiny since 2004, when Amnesty International published a ninety-two-page document reporting over 245 deaths temporally related to the use of the TASER. This document called for a rigorous and independent and impartial inquiry into their use and their effects.

Dr. Dennis and his colleagues at Cook County are continuing their pursuit of elucidating the possible physiology responsible for fatalities associated with the use of these electro-muscular incapacitation devices. This study demonstrates that the vector of electrical discharge in a trans-cardiac 
plane is associated with electocardiographic and echocardiographic evidence of cardiac capture and ventricular dysrhythmia.

In two instances, they have even demonstrated deterioration into ventricular fibrillation. I enjoyed reading the manuscript and I have several observations and questions for the authors.

Number one, your methods for this study utilize tensecond discharges of the TASER X26 in multiple vectors, for a total of sixty-seven discharges on four animals. Table 1 indicates that Animal A received six experimental discharges, while Animal B received nine, Animal C received twentyfour, and Animal D received twenty-eight.

The published information on the TASER X26 states that it is programmed for a five-second discharge and your last study utilized two forty-second discharges. Can you comment on your choice to use a ten-second discharge duration and how you controlled for the effect of multiple subsequent discharges on the same animal?

Specifically, did you monitor or correct for any physiologic parameters, such as $\mathrm{pH}, \mathrm{pCO} 2$, or lactic acid, after ventricular capture, to ensure that this would not contribute to the susceptibility of dysrhythmia on subsequent discharges?

The second question is your current study indicates that the ventricular fibrillation threshold can be reached with the unmodified TASER X26 if the correct ventral trans-cardiac vector is achieved in these twenty-five to thirty-six-kilogram pigs. However, previous work has shown that the ventricular fibrillation threshold is directly proportional to body mass index.

It would seem unlikely that these same discharges would be responsible for sudden death in the average seventy-kilogram human. How would you then explain that several reported deaths have also been associated with dry tasing or the drivestun mode, where the discharge is delivered by laying the TASER gun directly in contact with the skin? In these situations, no barbs are deployed into the human subject and thus, it would be much harder to create that trans-cardiac vector of electrical current.

My last question is the use of the anesthetized pig as the experimental model in the TASER research has been criticized, due to important anatomical and electrophysiologic differences between the pig and the human. The majority of deaths associated with the TASER have involved agitated victims under the influence of stimulatory drugs or with underlying cardiac abnormalities.

My question for you is do you think that the excited delirium that has been reported in humans will ever be able to be reproduced in the swine experimental model in the controlled laboratory?

Dr. Andrew Dennis (Chicago, Illinois): Thank you, Dr. Earley. Those are actually very insightful and I hope to do them justice. The first question, with regard to our choice of ten-second discharges, is based on our previous studies where we had used two 40 -second discharges. For this study, where we would be exposing the animals to multipe discharges, we elected to shorten each discharge.

As you stated, if you hold and release the trigger, the device will deliver a five-second discharge. However, it is not uncommon in the field that the tripper will be held and a continuous discharge will be delivered. A fully charged TASER X26 can discharge for upward of 10-15 minutes, that's 600-900 seconds, if the trigger is held down or if repeated 5-second discharges are given. It is not uncommon for discharges longer than 5-seconds to be used in the field and I am aware of a death that occurred after a prolonged, fifty-seven second discharge.

We chose to use ten-second discharges because we knew from our earlier studies that the forty-second discharges were not necessary to obtain cardiac capture. Capture occurs very rapidly, in one or two seconds, so really, the length of discharge was not the issue, as much as was the vector itself.

We did not correct in this study for $\mathrm{CO}_{2}$ or for $\mathrm{pH}$. What we learned from our previous studies was that, by using succinylcholine, we eliminated all the acidosis, even with the forty-second discharges. We did not control for that, because we felt pretty confident that the acidosis was not a function of cardiac depression, but in fact was a function of the skeletal muscle contractions, which were prevented in this model by the succinylcholine.

With regard to your other question, the TASER itself, there is one report indicating a trend relating decreased weight and ventricular fibrillation, but this finding has never been repeated and we did not see a weight or mass effect in our studies. The study that you are referring to, interestingly enough, did not use the TASER X26. They used what they termed a "TASER-like device" and there's a significant discrepancy in the literature between studies that used the "TASER-like device" versus an actual TASER X26. That study, using the "TASER-like device," reported that the amperage had to be ramped up by a factor of 10- to 15 -fold to reach the ventricular fibrillation threshold, but in our studies we saw VF repeatedly with the standard output of a fieldissue TASER X26. We could not and did not need to change the output power of the device to see VF.

With regard to the in-custody deaths referred to by Amnesty International, the biggest problem is that there is no database available that can be queried regarding deaths temporally associated with TASER use. It is nearly impossible to get the data from any medical examiner or police department in the U.S. regarding deaths and the details surrounding these deaths such as dart placement, discharge durations, and the number of discharges delivered. This type of information is essential before drawing any conclusions about these incustody deaths.

With regard to the anesthesia, you're right that we did not in this case mimic the excited delirium or agitation scenarios that are commonplace in the real world. This can be done and we're waiting to hear about a grant from NIJ for this exact study, where anesthetized animals are stimulated with 
cocaine, methamphetamine or epinephrine and their responses to TASER discharges are then determined. Since the phenomenon of excited delirium is thought to involve elevated core temperature, this parameter will be carefully monitored. Also, as you mentioned, there are some cardiac and other anatomic differences between swine and humans that may affect the results of studies such as ours. The results from animal studies must always bear the caveat that such differences exist, but swine anatomy and physiology are generally quite similar to humans in numerous ways. For this reason, swine have been used as the primary model in pacemaker and defibrillator studies and also in EID studies. I hope that answers your question.

Dr. Erik W. Streib (Indianapolis, Indiana): I would like to congratulate you on looking into something which obviously has a lot of ethical and political connotations regarding the use of this device in humans. I did have one question, which I think you partially answered, which is related to the animal model and the size of the animal. Is there any way of adjusting the dose, which I presume has been engineered for an adult human subject, to the size and the dimensions of your experimental model? Also, since these are frequently demonstrated on humans in the training process, have you considered monitoring the trainees in police training situations with EKG monitoring or echo imaging?

Dr. Andrew Dennis: Those are two very good questions. Regarding adjusting the TASER dose downward for use in animals that are smaller than adult males, nobody can do this with a police-issue TASER X26 or any other model of
TASER. As I mentioned earlier, there are a few studies that have used this "TASER-like device," where the output power can be varied. The mass/ VF relationship found in one study has not been repeated by anyone and there are several reasons to believe that it cannot be repeated with a standard X26. In practice, the output power of the X26 is not variable and the only thing you control is the discharge duration. Even if we accept the idea that there is a relationship between body mass and cardiac effects, it should be pointed out that in the field it is not uncommon for children or small adults to be tased. If they are a subpopulation with greater susceptibility to injury from TASERs, we should be aware of this.

With regard to the EKGs on human volunteers, we have tried to look at this and other investigators have looked at it. The main problem is that the TASER discharge completely obscures the EKG during the discharge, so rhythms before and shortly after discharges can be seen, but not during the discharge. It is during the discharge that the most interesting cardiac effects are seen. As a result, the EKG studies that have been reported on TASER trainees have shown no effects. So if the EKGs have no value can you use echo? This may be possible, but movement artifacts will be highly problematic in conscious humans and the vectors that are likely to have cardiac effects, as demonstrated here, will be potentially dangerous for the subject. In all of the studies reported thus far on human volunteers, the vector has been non-trans-cardiac and the majority of them are dorsal where, in our model, we saw no cardiac capture. Our IRB will not permit us to do any of these studies. They consider them to be too hazardous. 